(4) Toxic Wareham soil, partially sterilized to remove its toxicity, regains its toxicity in about ten days after inoculation with untreated soil. This is confirmation that toxicity is associated with the activity of some organism.

(5) Small weighed samples of cellulose may be recovered unchanged after being buried four months in Wareham soil ; similar samples undergo considerable or complete decomposition in fertile woodland soil, or in Wareham soil to which compost has been added, as a consequence of fungal attack. The inhibitory action of Wareham soil thus extends to the fungi responsible for cellulose decomposition. There appears to be a direct correlation between rate of cellulose decomposition in a soil and its fertility as measured by tree growth.

To summarize: it has been shown by these methods that Wareham soil and soils like it contain a 'toxin' which inhibits growth of fungi such as air-borne moulds and mildews; some, at least, of the mycorrhiza-formers ; and those responsible for cellulose decomposition in the soil. It has also been shown that this toxin results from the metabolic activity of some organism, such activity representing a course of humus decomposition largely absent in fertile soils.

${ }^{1}$ Rayner, M. C., Forestry, 1934-39.

\title{
SURFACE TEMPERATURES OF THE STARS
}

$\mathrm{T}^{\mathrm{H}}$ HE abandonment of the 1939 British Association meeting at Dundee involved, among other things, the cancellation of what promised to be a discussion of great interest on the temperatures of stellar surfaces. Fortunately, however, Prof. W. M. H. Greaves's opening address on the subject appears in the October number of the Observatory magazine $(62,252 ; 1939)$. In his review of the present position, Prof. Greaves directs attention to the way in which recent observations-notably the colour temperature measurements carried out during the last ten years in England, Germany and France-have forced astrophysicists to the conclusion that no unique meaning can now be attached to the phrase 'the temperature of a star', because a stellar surface does not radiate even approximately as a black body.

The fundamental assumption of the early theory was that the total absorption coefficient of stellar material is not a function of the frequency of the radiation absorbed. The first deduction from this hypothesis is that the effective temperature of the radiation at any point in the star is equal to the temperature of the stellar matter at that point. From this in turn it follows that the star as a whole should behave very much as a black body, so far as its surface radiation is concerned; and on this conclusion is based the Fowler-Milne scale of ionization temperatures. But, unfortunately, the work on stellar colour temperatures developed at Greenwich, at Göttingen, and at Jungfraujoch leads to a totally different scale of temperatures. This disagreement between conclusions based on one hand upon direct experiment, and on the other upon an ad hoc hypothesis (for which little justification but mathematical convenience existed in the first place), has naturally proved fatal for the hypothesis.
The collapse of the assumption was not, however, entirely unexpected. The mere existence of discontinuities in stellar continua at the heads of absorption line series (notably at the Balmer limit) suggests that there is something seriously wrong with it. But in addition to this, the apparent breakdown of the Fowler-Milne scale of stellar temperatures has recently given an impetus to the mathematical investigation of various atoms with a view of determining if their absorption coefficients vary between the series limits. The work shows beyond doubt that such variation does exist, and it even predicts the type of variation for such simple atoms as those of hydrogen and the alkali metals. On the assumption that the absorption coefficient of hydrogen varies with the cube of the wave-length, Pannekoek (Astrophys. J., 84, 481; 1936) finds that in an $A 0$ star, where hydrogen is the main contributor to the spectrum, the colour temperature measured in the visual region should indeed be of the order of that observed, namely, nearly twice the effective temperature, simply as a result of this variation. At the lower temperatures of later-type stars, the more complex metallic atoms play a large part in the absorption; and beyond the qualitative result that the variation of metallic absorption coefficients with wave-length is in the opposite sense to the variation in hydrogen, little progress can yet be recorded in this direction.

Prof. Greaves concludes that future advances will call for contributions from the mathematician, in developing his treatment of the difficult general problem which allows for variability in the total absorption coefficient; from the physicist, in making laboratory measurements of the various atomic absorption coefficients; and from the astronomer, in devising and carrying out checks on theory as it develops. 
A new method of obtaining the surface temperatures of stars directly from observation is announced by MM. Barbier and Chalonge in a paper following Prof. Greaves's address (loc. cit., p. 273). These authors, recognizing the paucity of experimental information on atomic absorption coefficients, avoid their use altogether by dealing only with those early-type stars for which the total absorption coefficient is sufficiently great for the surface to radiate effectively as a black body. The criterion they use for selecting such stars is the size of the Balmer discontinuity: where this is large, the opacity below the Balmer limit will evidently be great. In this case there is a good chance that the radiation seen will originate mainly in the outer surface layers, the temperature of which will then be what is directly observed as the colour temperature of the star.
Evidence for this view is provided by observations of the eclipsing variable star Algol. The ultra-violet colour temperature of this star (which is typical, as to size of Balmer discontinuity, of the other stars considered) is found to be independent of the phase of the eclipse. Evidently the radiation from the centre of the disk is identical in composition with that from the limb (which is, of course, surface radiation). In this case, then, and by extension in the others also, the observed colour temperature is actually the effective temperature of the surface layers. The mean value for the $A_{0}$ stars selected is $12,500^{\circ} \mathrm{K}$., which is in fair agreement with the ionization temperature.

This valuable method of attack thus brings still nearer the prospect of reconciling the various 'temperatures' which can be assigned to stellar surfaces.

A. H.

\section{OBITUARIES}

The Earl of Crawford and Balcarres, K.T., F.R.S.

$\mathrm{W}^{\mathrm{s}}$ E record with deep regret the death of the Earl of Crawford and Balcarres, which took place at Haigh Hall, Wigan, on March 8, at the age of sixty: eight years.

The Right Hon. Sir David Alexander Edward Lindsay was born on October 10, 1871, and succeeded his father in 1913 as twenty-seventh Earl of Crawford and as holder of other titles in the peerages of Scotland and the United Kingdom. He was educated at Eton and Magdalen College, Oxford, where he graduated in 1894 with first class honours in history. He afterwards entered upon a political career, and sat in the House of Commons, holding office on occasion, until he inherited the family titles. During the War of 1914-18 he served in France as a private and as a second lieutenant until in 1916 he was recalled to England to take up office as president of the Board of Agriculture and Fisheries. Later he held other offices in the Government, among them that of First Commissioner of Works, $1921-22$.

Lord Crawford's interest in, and knowledge of, art and archæology were both widespread and profound; and in the performance of his duties as First Commissioner of Works, he was brought into close touch with conditions affecting archæological studies in Great Britain. Of this he made full and effective use both as president of the Society of Antiquaries and as a prominent figure in the various organizations which have had as their object the preservation of the antiquities, monuments and amenities of town and countryside in Great Britain. His charm and his personality, as well as his public experience and knowledge, made him an invaluable and most effective leader in any and every cause in which the interests of archæology were concerned, and it was owing very largely to his influence and persuasive powers that public and official interest in British antiquities was stimulated in post-War years to greater activity in archæological exploration and also in preserving such relics of the past as remain from an over-zealous desire for improvement or the inroads of commercialism.

Lord Crawford had already acquired a considerable reputation as a scholar in artistic and antiquarian studies, notably in the field of Italian art, before his official connexion with the Office of Works. He published his well-known "Evolution of Italian Sculpture" in 1910. He was a trustee of the National Gallery and the National Portrait Gallery, and in 1923 became a trustee of the British Museum. He was chairman of the Fine Art Commission and a member of the Royal Commissions on Historical Manuscripts and Ancient Monuments, as well as of the council of the British School of Archæology at Rome. His academic achievement and services to archæological studies were recognized by honorary degrees of the Universities of St. Andrews, Cambridge, Edinburgh and Manchester. Of the lastnamed University he was the chancellor, succeeding the late Lord Morley in 1923. As chancellor, he took a very keen and active interest in the affairs of the University. In the following year came his election as a fellow of the Royal Society.

Lord Crawford's death will be mourned on personal grounds by all who knew him; it is no less a serious loss to the cause of humane studies, and comes at a moment when so outstanding a personality ean ill be spared. 